\title{
経頭蓋カラードプラ法の脳動脈瘤破裂後脳血管攣縮評価 における有用性
}

\author{
竹島靖浩 ${ }^{1}$ 川口正一郎 ${ }^{2}$ 田村健太郎 ${ }^{1}$ 榊 寿右 \\ 斉藤こずえ ${ }^{3}$ 上野 聡 $^{3}$ \\ 1 奈良県立医科大学 脳神経外科 \\ 2 奈良県立奈良病院 脳神経外科 \\ 3 奈良県立医科大学 神経内科
}

\section{Usefulness of transcranial color flow imaging (TCCFI) to evaluate vasospasm after aneurysmal rupture}

\author{
Kozue Saito ${ }^{3}$, Satoshi Ueno ${ }^{3}$ \\ ${ }^{1}$ Department of Neurosurgery, Nara Medical University, Kashihara, Japan \\ ${ }^{2}$ Department of Neurology, Nara Medical University, Kashihara, Japan \\ ${ }^{3}$ Department of Neurosurgery, Nara Prefectural Nara Hospital, Nara, Japan
}

Yasuhiro Takeshima', Shoichiro Kawaguchi ${ }^{2}$, Kentaro Tamura', Toshisuke Sakaki

Objective : To assess the usefulness of transcranial color flow imaging (TCCFI) for vasospasm, we evaluated the flow velocities in the middle cerebral artery (MCA) and anterior cerebral artery (ACA) using TCCFI in patients with subarachnoid hemorrhage (SAH) due to aneurysmal rupture.

Methods : Clinical results were obtained in 14 consecutive patients who suffered SAH due to aneurysmal rupture and underwent neurosurgical procedures between December 2004 and September 2005. Using TCCFI, the MCA and ACA were detected and their peak systolic flow velocities (Vs) were determined on days 3,7, and 14 .

Results : Almost all of the 14 patients had a good outcome (GR 11 cases, MD 2 cases, SD 1 case, dead 0 case). There was no significant increase of M1 and A1 Vs with time. Symptomatic vasospasm was observed in 3 patients, all of whom were elderly, deteriorated after day 8 , and in whom a rise in $\mathrm{M} 2 \mathrm{Vs}$ preceded the symptoms.

Conclusion: TCCFI appears to be useful for evaluation of vasospasm, especially in the M2 segment.

Key words: TCCFI, vasospasm, M2 segment

\section{はじめに}

破裂脳動脈瘤によるくも膜下出血後の遅発性脳血管攣縮 は、いまだ予後に大きく影響する因子のひとつ ${ }^{11)}$ であ、臨 床においては、症候性とならないように早急に対応するた め症例ごとの的確な診断が必要である，経頭蓋ドプラ（TCD） は非侵襲的検査法として多用されてきたものの、中大脳動 脈分岐部より末梢の血管攣縮を見つけることは困難とされ ている ${ }^{10,12)}$ 。一方、経頭蓋カラードプラ法（TCCFI）は血管 の解剖学的位置関係が把握でき、より末梢の血流速度を測 定しうるとされるが吕)、破裂脳動脈瘤の術後経過について の報告はまだ少ない.

今回、破裂脳動脈瘤䅡部クリッピング術急性期施行例で、
TCCFI を用いて患側中大脳動脈水平部 (M1)、島部 (M2)、 前大脳動脈水平部（A1）の血流速度を経時的に観察し、そ の有用性について検討したので報告する.

\section{対象・方法}

著者らの施設では、2004 年 12 月より破裂脳動脈瘤による くも膜下出血に対してクリッピング術施行後 TCCFIにより 脳血管攣縮の評価を行っている。そのうち、2004 年 12 月か ら 2005 年 9 月までで発症 72 時間以内に開頭クリッピング 術が行われたウイリス輪前半部破裂脳動脈瘤症例で、TCCFI による頭蓋内血管の評価が可能であった 14 症例を対象とし た.

14 症例の年齢は 42-85 歳（平均年齢 70.5 歳）で、性別・

Reprint request

竹島靖浩：=634-8522 奈良県橿原市四条町 840 奈良県立医科大学 脳神経外科

Yasuhiro Takeshima : Department of Neurosurgery, Nara Medical University, 840 Shijo-cho, Kashihara, Nara 634-8522, Japan

〔Received Aug 24, 2007 ; Accepted Oct 24, 2007〕 
動脈㢚の部位・神経学的 grading ・ CT grading等についてTable 1 に示した。症候性脳血管攣縮は、くも膜下出血発症後 3 日 目以降に新たに出現する意識・言語・運動障害などの神経 脱落症状とし、手術 ·脳内血腫 ·頭蓋内圧克進等に起因す るものを除外した. 14 例中 3 例 (21.5\%) で症候性脳血管攣 縮が認められ、1例 (7.1\%) でCT 上低吸収域を呈した。術 3 カ月後の予後は Glasgow outcome scale (GOS) で GR11 例 (78.6\%)、MD 2例 (14.3\%)、SD 1例 $(7.1 \%)$ であっ た.

全例術直後より脳血管攣縮予防目的に塩酸ジルチアゼム を経静脈的に 2 週間持続投与（3〜 $5 \mu \mathrm{g} / \mathrm{kg} / \mathrm{min})$ した，循環 管理は normovolemia、normotension とし、他の脳血管攣縮予 防薬は投与しなかった。全例で塩酸ジルチアゼム投与によ る徐脈、血圧低下は認めなかった。

TCCFI は TOSHIBA NEMIO により $2 \mathrm{MHz}$ (pulsed-rate) の セクタ型プローブを用い、脳血管攣縮初期・ 中期 · 後期と してそれぞれ術 3 日後・7 日後・14 日後に同一検者にて施 行した。患側側頭部から患側 M1、M2、A1 の収縮期最高血 流速度 $(\mathrm{Vs})$ と時間平均血流速度 $(\mathrm{Vm})$ を計測し、経時的 に観察した。破裂前交通動脈瘤症例では手術側を患側とし た. 血流速度值は平均值士標準誤差で表示し、統計学的処 理はStudent t-test を用いて行い、 $\mathrm{p}<0.05$ で有意差ありと判 断した.

Table. 1 : Characteristics of 14 patients with aneurysmal SAH

\begin{tabular}{ll}
\hline \multicolumn{1}{c}{ Characteristics } & No. of patients(\%) \\
\hline Sex & \\
M & $5(36)$ \\
F & $9(64)$ \\
Aneurysmal location & \\
MCA & $4(29)$ \\
Anterior communicating artery & $3(21)$ \\
ICA & $6(43)$ \\
Anterior cerebral artery & $1(7)$ \\
WFNS grade & \\
I & $7(50)$ \\
II & $2(14)$ \\
III & $0(0)$ \\
IV & $2(14)$ \\
V & $3(21)$ \\
Hunt \& Kosnik grade & \\
I $\cdot$ II & $8(57)$ \\
III & $1(7)$ \\
IV $•$ V & $5(36)$ \\
Fisher CT grade & \\
I & $0(0)$ \\
II & $1(7)$ \\
III & $10(71)$ \\
IV & $3(21)$ \\
\hline
\end{tabular}

\section{結 果}

$\mathrm{TCCFI}$ による患側平均 $\mathrm{Vs} \cdot \mathrm{Vm}$ の経時的変化は、M1 (Figure 2)、A1（Figure 3)、M2（Figure 4）に示した. 初回 検査時の平均 Vs は、 $\mathrm{M} 1: 134.6 \pm 51.6 \mathrm{~cm} / \mathrm{sec} 、 \mathrm{~A} 1: 120.2$ $\pm 54.6 \mathrm{~cm} / \mathrm{sec} 、 \mathrm{M} 2: 109.3 \pm 41.6 \mathrm{~cm} / \mathrm{sec}$ と著明な上昇はな く、経過中何れの部位でも有意な変化はなかった.

症候性脳血管攣縮を認めた 3 例は、いずれも 70 歳以上で 術後8日以上経過した比較的後期に症候性となり、M1のVs $\mathrm{Vm}$ に著明な上昇はなく $\mathrm{M} 2$ の $\mathrm{Vs} \cdot \mathrm{Vm}$ の上昇がそれに先行 もしくは平行して認められた。(代表症例 1,9)

M1 の攣縮を示す指標とされる Vs：200 cm/ sec またはVm： $120 \mathrm{~cm} / \mathrm{sec}$ 以上を呈したのは 2 例で、ともに 70 歳以上の高 齢者であったが、2 例とも症候性とはならなかった。

\section{代表症例}

症例 $1: 78$ 歳男性の破裂左前脈絡動脈瘤の症例（Hunt \& Kosnik grade IV) でday 0 に手術を行った. 術後すみやか に意識障害改善し良好に経過していた。Day 7 の TCCFI では流速上昇を認めなかったが、Day 8 の脳血管撮影にて Lt. A1 と Lt.M2 に高度の脳血管攣縮を認めたため厳重に管理 していた. Day 14 の TCCFI では患側 M1・M2・A1のVs/ $\mathrm{Vm}$ が 151/98・208/29・171/108 cm/ $/ \mathrm{sec}$ と著明な上昇を認め、 M2・A1 で脳血管攣縮が疑われた。 その後 Day 18 に見当識 障害を呈した. Hypervolemia・hypertension 療法を行い症状 改善し、GR で退院した. (Figure 5)

症例 9:83 歳女性の破裂左後交通動脈瘤の症例（Hunt \& Kosnik grade II) で、day 2 に手術を行った. Day 7 の TCCFI では患側 M1・M2・A1のVs/Vm が94/51・61/32・ $155 / 93 \mathrm{~cm} / \mathrm{sec}$ であったのが、右下肢麻疩を認めたday 14 に はそれぞれ、65/39・267/145・151/101 cm/secへと変化し、 M2・A1 で脳血管攣縮が疑われた. Hypervolemia 療法を行い 厳重に管理した。 Day 17 の頭部 CT では、右 MCA 分水界領 域の脳梗塞を認めた。 Day18の SPECT では両側 ACA 領域 ならびに右 MCA の分水界領域に血流低下を認めた. Day 22 に脳血管撮影を施行したところ、Lt. A1 と Lt. M2 に高度の 脳血管攣縮が確認された。 Day 24 に脳室腹腔短絡術を施行 した後徐々に麻痺も改善し GR となった. (Figure 6)

\section{考察}

くも膜下出血による脳血管攣縮の完全な予防手段がいま だ存在しない以上、早期発見・早期治療がますます重要と なってくる．観血的かつ侵襲的な検査である脳血管撮影と 比べ、Aaslid らの報告 ${ }^{1}$ 以来近年発達してきた TCD は、観察 対象が血流速度であり実際の脳血管攣縮の程度以外にも生 理学的要素である血圧 · 心拍出量 ·循環血液量等の影響を 受ける ${ }^{2)}$ こ、検者間での測定值の差異が生じうるなどの問 題点があるものの、非侵襲的で反復可能であり、脳血管攣 縮の検査法として広まってきた2,5,8).これまで主幹動脈の脳 


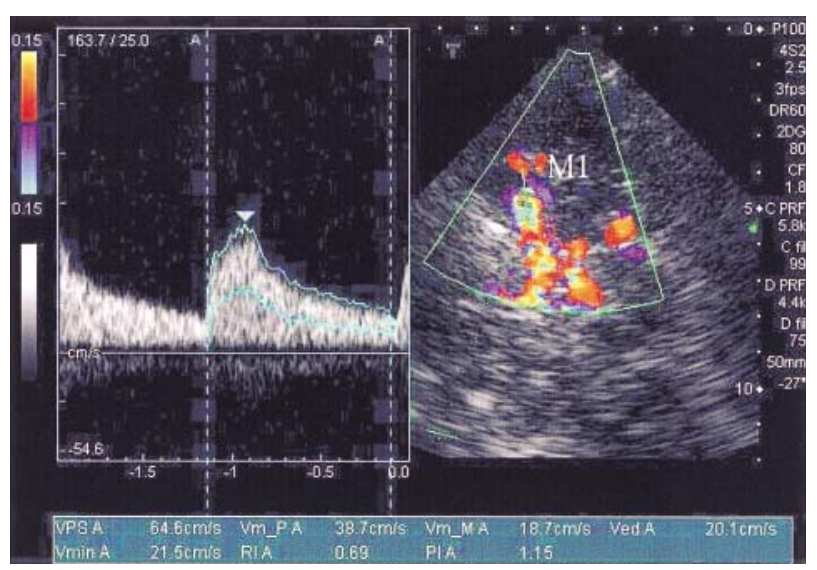

Figure 1: TCCFI demonstrated continuous cerebral vessels from IC to MCA. Flow velocity of M1 segment was measured by D-mode.

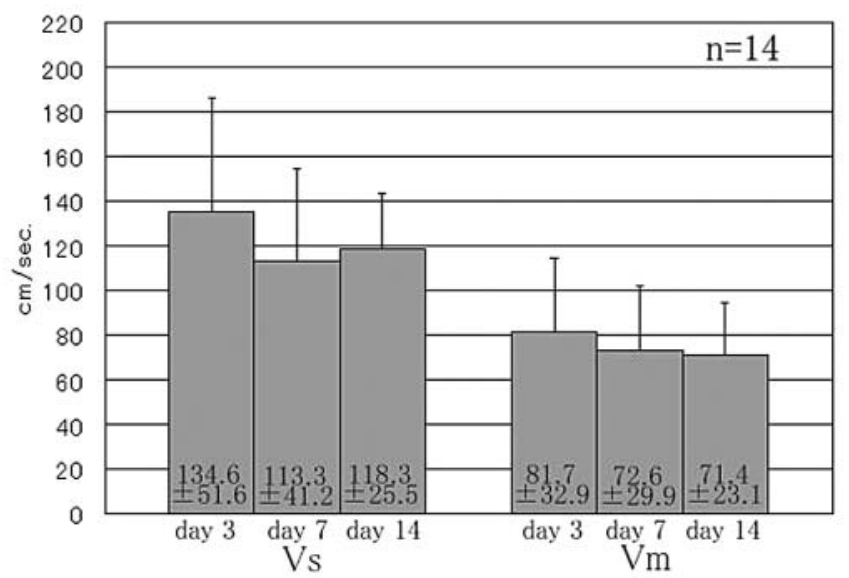

Figure 2:M1 flow velocities (Vs, Vm) were showed. There was no significant difference between each of them as time passes.

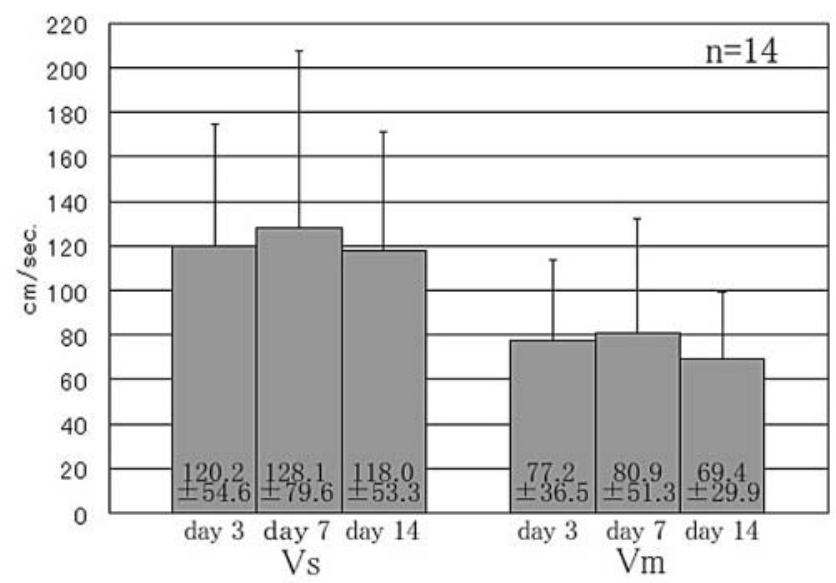

Figure $3:$ Al flow velocities $(\mathrm{Vs}, \mathrm{Vm})$ were showed. There was no significant difference between each of them as time passes.

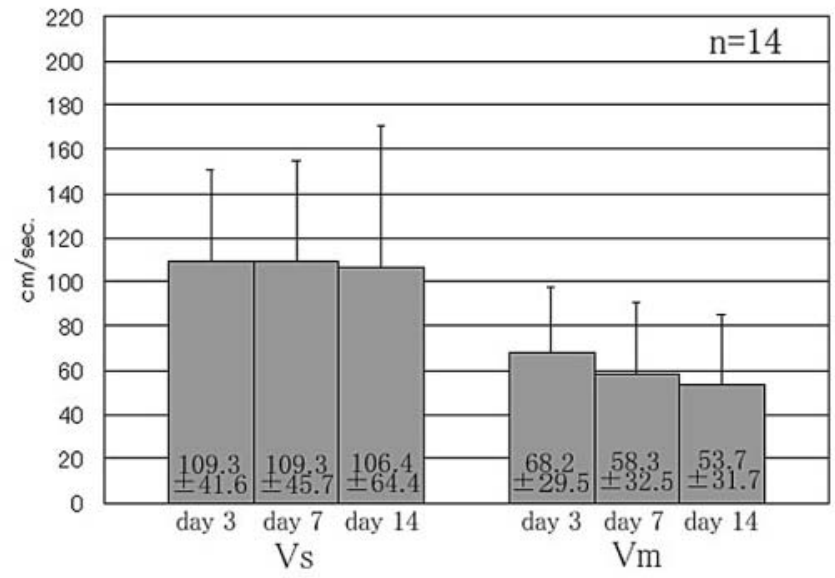

Figure $4: \mathbf{M} 2$ flow velocities $(\mathrm{Vs}, \mathrm{Vm}$ ) were showed. There was no significant difference between each of them as time passes.

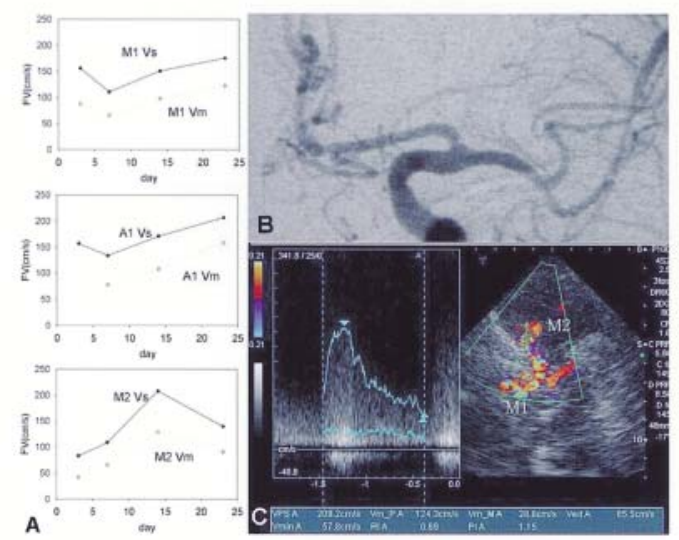

Figure $5: \mathrm{A}$ : Blood flow velocities in the Lt. M1, M2 and A1 portion (case 1). Lt. A1 and M2 flow velocities increased from day 7.

B : Angiograph taken on day 8 (case 1), showing moderate vasospasm on Lt. A1 and M2 portion.

$\mathrm{C}$ :TCCFI finding at day 14 (case 1). M2 artery was evaluated and had high blood velocity.

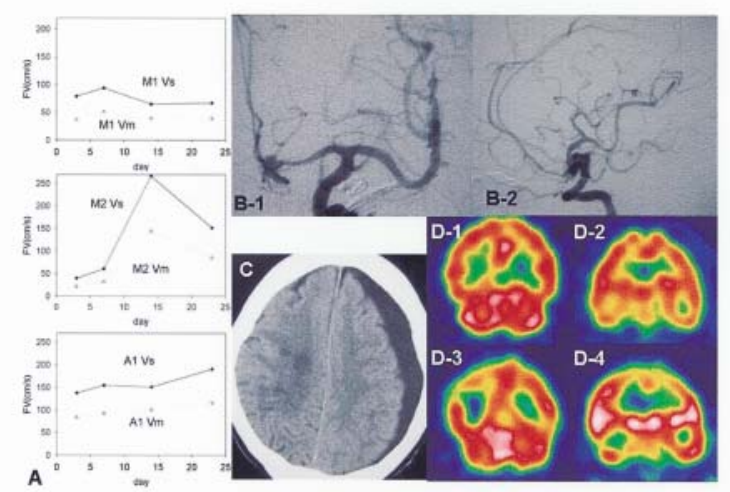

Figure $6: \mathrm{A}$ : Blood flow velocities in the Lt. M1, M2 and A1 portion (case 9). Lt. A1 velocity increased from day 7 to day 23 , and $\mathrm{M} 2$ velocity elevated at day 14 .

B-1\&B-2 : Angiographs taken on day 22 (case 9), showing severe vasospasm on Lt. A1 and M2 portion.

C : CT taken on day 17 revealed rt.MCA watershed infarction. $\mathrm{D}$ : These regions were correlated with the regions that showed hypoperfusion by SPECT, 3 days before symptomatic vasospasm (D-1,2: day 11) and after symptomatic vasospasm (D-3, 4 day 18). 
血管攣縮が主に議論されてきたが、末梢側の局所的な攣縮 のために後遺症を残しその後の ADL の低下を余儀なくされ る症例も実際多く、未梢血管の評価は臨床的には大変重要 である．最近では TCCFI の導入により、M2 をはじめとした このような末梢血管の血流速度の正確な評価が、角度補正 が行えることで経時的にも可能となってきている ${ }^{4,8)}$.

TCCFI を用いた本研究では、破裂脳動脈瘤によるくも膜 下出血で急性期に脳動脈瘤頚部クリッピング術を施行した 症例で、 $\mathrm{M} 1 \cdot \mathrm{A} 1 \cdot \mathrm{M} 2$ の $\mathrm{Vs} \cdot \mathrm{Vm}$ の有意な上昇は術後 2 週 間認めなかった。過去の文献では、脳血管攣縮予防に Nimodipine を投与した 22 例でM1 の Vm が第 2-3 病日で平 均 $81.5 \mathrm{~cm} / \mathrm{sec}$ 、第 7 病日で $144.5 \mathrm{~cm} / \mathrm{sec}$ であったという報 告9) や、hypervolemia 療法を行った 21 例で M1 の Vs と Vm がそれぞれ $158.8 \mathrm{~cm} / \mathrm{sec}$ と $102.5 \mathrm{~cm} / \mathrm{sec} 、 \mathrm{M} 2$ の Vs と Vm がそれぞれ $125.4 \mathrm{~cm} / \mathrm{sec}$ と $82.5 \mathrm{~cm} / \mathrm{sec}$ という報告 ${ }^{4}$ がある. Figure 2 に示す M1 の Vs ・ Vm の結果はこれらの值との比較 においても、初回值かつその後の経過も良好な成績であり、 本研究での 3 ヶ月後の予後も GR78.6\%、MD14.3\%、SD $7.1 \%$ と良好であった。

今回、M1 での血流上昇を認めるものの虚血症状を呈しな かった症例や、M1 の脳血管攣縮が重度ではなくとも末梢側 の M2 の血流が 7 日目以降に有意に上昇し遅発性に症候性と なる症例が存在し、これらは全て 70 歳以上の高齢者であっ た．年齢と脳血管攣縮との関係について文献では、動脈硬 化性变化のために脳血管撮影上の主幹動脈の攣縮の頻度は 加齢とともに減少する ${ }^{15)}$ とするものや、高齢者では脳血管撮 影上の攣縮の程度は径が大きい内澒動脈ほど軽度であった とするもの、脳血管撮影上の主幹動脈の攣縮に年齢差はな いものの高齢者では有意に症候性となることが多かった ${ }^{6)}$ する報告もある，高齢者においては TCD の正常值は低くな

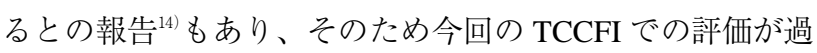
小評価となっている可能性があると考えられた。また、末 梢動脈の脳血管攣縮だけでは、遅発性神経脱落症状は認め にくいとされる報告 ${ }^{10)}$ がある一方、M2 の血流速度が症候性 脳血管攣縮と関係があるとの報告(4)もる。症候性となるた めには様々な要素が関与するが、中枢側の血管では脳血管 攣縮が軽度であるとされる高齢者においては、種々の予備 能の低下や虚血に対する耐性の低下が強く作用し、特に末 梢側・亜急性期にその影響が強く現れるものと考えられ、亜 急性期の術後にも、特に高齢者では末梢側の血流速度も含 めより一層注意する必要があり、それには末梢血管の描出・ 評価に優れる TCCFI が有用であると考えられた。

脳血管攣縮と TCD の関連性について、現時点では M1 の 血流速度に関するコンセンサスしか得られていない7,8,9). し かし、TCCFIの出現によってより末梢の血管が経時的に評 価可能となってきており ${ }^{4)}$ 、今後他の部位における評価も進 んでいくと考えられる.しかし現時点では TCCFIは必ずし も常に計測可能というわけでなく、今回の研究でも、術後 の血腫のため、また骨空より遠い部位のために描出不能で
除外せざるを得ない症例も存在した，TCCFI は非侵襲的で 反復した検査も可能なだけに、エコー機器の発達と超音波 造影剂等を利用した診断技術のさらなる進歩により、より 末梢の血管も含めた他の部位においても脳血管攣縮がより 容易に、かつより確実に評価可能となり、臨床の現場にお いて早期診断・早期治療に今以上に応用されることが望ま れる。

当施設ではくも膜下出血に伴う遅発性神経脱落症状出現 予防目的に、Ca 拮抗薬である塩酸ジルチアゼム静脈内単独 持続投与を行っている ${ }^{13}$ が、今回の結果と塩酸ジルチアゼム 投与の関連については、更なる検討を要すると考えられる. また、今回は対象例も少なく観察間隔も長かったため、今 後症例を増やしょり頻回に TCCFIにて観察して更なる検討 を加えることが必要と考えられる。

\section{結語}

急性期破裂脳動脈瘤澒部クリッピング術後に、TCCFI により頭蓋内血管を観察した。

高齢者においては術後亜急性期にも末梢側も含めた脳血 管攣縮の観察が必要であり、それには TCCFI が有用である ことが示唆された。

\section{引用文献}

1) Aaslid R, Nornes $H$ : Noninvasive transcranial Doppler ultrasound recording of flow velocities in basal cerebral arteries. J Neurosurg 57 : 769-774, 1982

2) Aaslid R: Transcranial Dopplar assessment of cerebral vasospasm. Europian Journal of Ultrasound 16 :3-10, 2002

3) Inagawa $T$ : Cerebral vasospasm in elderly patients with ruptured intracranial aneurysms. Surg Neurol 36:9198, 1991

4）唐沢洲夫，金井秀樹，山下伸子，杉山尚武，福岡秀和： Transcranial color-corded Duplex sonography を用いたクモ 膜下出血後の M1-M2 の症候性血管攣縮についての検討. Neurosonology 17 : 125-131, 2004

5) Krejza J, Kochanowicz J, Mariak Z, Lewko J, Melhem ER : Middle Cerebral Artery Spasm after Subarachnoid Hemorrhage: Detection with Transcranial Color-coded Duplex US. Radiology 236 : 621-629, 2005

6) Lanzino G, Kassell NF, Germanson TP, Kongable GL, Truskowski LL, Torner JC, Jane JA : Age and outcome after aneurysmal subarachnoid hemorrhage : why do older patients fare worse? J Neurosurg $85:$ 410-418, 1996

7) Lysakowski C, Walder B, Costanza MC, Tramèr MR : Transcranial Dopplar Versus Angiography in Patients With Vasospasm due to a Ruptured Cerebral Aneurysm A systematic Review. Stroke 32 : 2292-2298, 2001

8) Mariak Z, Krejza J, Swiercz M, Kordecki K, Lewko J : Accuracy of transcranial color Doppler ultrasonography in the 
diagnosis of middle cerebral artery spasm determined by receiver operating characteristic analysis. J Neurosurg 96 : 323-330, 2002

9) Mascia L, Fedorko L, terBrugge K, Filippini C, Pizzio M, Ranieri VM, Wallace MC: The accuracy of transcranial Dopplar to detect vasospasm in patients with aneurysmal subarachnoid hemorrhage. Intensive Care Med 29 : 10881094, 2003

10) Newell DW., Grady M., Eskride JM Winn HR : Distrubution of angiographic vasospasm after subarachnoid hemorrhage : implication for diagnosis by transcranial Doppler ultrasonography. Neurosurg 27 :574-577, 1990

11) Proust F, Hannequin D, Longlois O, Freger P, Creissard P : Cause of morbidity and mortality after ruptured aneurysm surgery in a series of 230 patients: The importance of control angiography. Stroke 26 : 1553-1557, 1995
12) Sloan MA, Harley EC Jr, Kassell NF, Henry ML, Stewart SR, Beskin RR, Sevilla EA, Torner JC: Sensitivity and specificity of transcranial Doppler ultrasonography in the diagnosis of vasospasm following subarachnoid hemorrhage. Neurology $39: 1514-1518,1989$

13）田村健太郎, 橋本宏之, 飯田淳一, 川口正一郎, 榊 寿右：〈も膜下出血に伴う脳血管攣縮に対する塩酸ジル チアゼムの臨床的効果. 脳血管攣縮 20：101-104，2004

14) Torbey MT., Hauser TK., Bhardwaj A, Williams MA., Ulatowski JA., Mirski MA., Razumovsky AY : Effect of age on cerebral blood flow velocity and incidence of vasospasm after aneurysmal subarachnoidhemorrhage. Stroke 32 : 20052011, 2001

15) Yoshimoto Y, Kwak S: Age-related multifactorial causes of neurological deterioration after early surgery for aneurismal subarachnoid hemorrhage. J Neurosurg 83 : 984-988, 1995 